\title{
Low back pain risk factors in a large rural Australian Aboriginal community. An opportunity for managing co-morbidities? Dein Vindigni*1, Bruce F Walker ${ }^{2}$, Jennifer R Jamison ${ }^{3}$, Cliff Da Costa ${ }^{4}$, Lynne Parkinson ${ }^{5}$ and Steve Blunden ${ }^{6}$
}

Address: ${ }^{1}$ Private practice of chiropractic, 12 David Street, Lalor, Victoria, 3075, Australia, ${ }^{2}$ School of Medicine, James Cook University, Townsville, Queensland, Australia, ${ }^{3}$ School of Chiropractic, Murdoch University, Western Australia, ${ }^{4}$ School of Mathematical \& Geospatial Sciences, RMIT University, Melbourne, Australia, ${ }^{5}$ Centre for Research and Education in Ageing, Faculty of Health, The University of Newcastle, New South Wales, Australia and ${ }^{6}$ Chief Executive Officer, Durri Aboriginal Corporation Medical Service, Kempsey, New South Wales, Australia

Email: Dein Vindigni* - dein@optusnet.com.au; Bruce F Walker - spine@optusnet.com.au; Jennifer R Jamison - J.Jamison@murdoch.edu.au; Cliff Da Costa - cliff.dacosta@rmit.edu.au; Lynne Parkinson - Lynne.Parkinson@newcastle.edu.au; Steve Blunden - sblunden@durri.org.au

* Corresponding author

Published: 30 September 2005

Chiropractic \& Osteopathy 2005, 13:21 doi:10.1186/1746-1340-13-21
Received: 20 May 2005

Accepted: 30 September 2005

This article is available from: http://www.chiroandosteo.com/content//3/I/2I

(c) 2005 Vindigni et al; licensee BioMed Central Ltd.

This is an Open Access article distributed under the terms of the Creative Commons Attribution License (http://creativecommons.org/licenses/by/2.0), which permits unrestricted use, distribution, and reproduction in any medium, provided the original work is properly cited.

\begin{abstract}
Background: Low back pain (LBP) is the most prevalent musculo-skeletal condition in rural and remote Australian Aboriginal communities. Smoking, physical inactivity and obesity are also prevalent amongst Indigenous people contributing to lifestyle diseases and concurrently to the high burden of low back pain.

Objectives: This paper aims to examine the association between LBP and modifiable risk factors in a large rural Indigenous community as a basis for informing a musculo-skeletal and related health promotion program.

Methods: A community Advisory Group (CAG) comprising Elders, Aboriginal Health Workers, academics, nurses, a general practitioner and chiropractors assisted in the development of measures to assess self-reported musculo-skeletal conditions including LBP risk factors. The Kempsey survey included a community-based survey administered by Aboriginal Health Workers followed by a clinical assessment conducted by chiropractors.
\end{abstract}

Results: Age and gender characteristics of this Indigenous sample $(n=189)$ were comparable to those reported in previous Australian Bureau of Statistics (ABS) studies of the broader Indigenous population. A history of traumatic events was highly prevalent in the community, as were occupational risk factors. Thirty-four percent of participants reported a previous history of LBP. Sporting injuries were associated with multiple musculo-skeletal conditions, including LBP. Those reporting high levels of pain were often overweight or obese and obesity was associated with self-reported low back strain. Common barriers to medical management of LBP included an attitude of being able to cope with pain, poor health, and the lack of affordable and appropriate health care services.

Though many of the modifiable risk factors known to be associated with LBP were highly prevalent in this study, none of these were statistically associated with LBP.

Conclusion: Addressing particular modifiable risk factors associated with LBP such as smoking, physical inactivity and obesity may also present a wider opportunity to prevent and manage the high burden of illness imposed by co-morbidities such as heart disease and type- 2 diabetes. 


\section{Background}

Low back pain (LBP) is the most prevalent musculo-skeletal condition in rural and remote communities [1-3]. Indigenous people in these communities are over-represented in low-skilled, manual jobs and the communityservice sector [4]. As such they are more likely to be exposed to greater manual handling of loads, repetitive strains and risk of musculo-skeletal conditions. Formal reporting of such conditions in the Australian Indigenous community is infrequent [1]. These occupational factors and resulting LBP may be compounded by lifestyle risk factors including smoking, physical inactivity, and obesity [5].

There is an abundance of literature reporting on the risk factors associated with LBP in the general population [6]. Known modifiable risk factors for low back pain are lack of fitness, poor health, obesity, smoking, drug dependence, and occupational factors including heavy lifting, twisting, bending, stooping, awkward posture at work and prolonged sitting. Those that are non-modifiable are increasing age, number of children, a previous episode of LBP and major scoliosis [6]. Within the public health context it is important to prevent injuries and painful conditions by addressing modifiable risk factors [7-9].

Australian Indigenous communities experience sub-optimal mortality and morbidity rates. As such it has been argued that by adopting a holistic approach and addressing modifiable risk factors associated with LBP, such as smoking, physical inactivity and obesity, the clinical management of co-morbidities such as heart disease and diabetes may also be partially addressed [10]. Exercise, for example, has been reported as the single most important lifestyle factor for preventing and managing insulin resistance especially among those who are obese $[11,12]$ It is also known that once their presenting musculoskeletal condition has been effectively managed, patients are more likely to comply with their practitioner's advice to promote other aspects of their health including weight loss and increased physical activity [10].

Modifiable risk factors for LBP mentioned above have been further classified as lifestyle (physical inactivity, poor muscle strength, obesity, smoking), and occupational (heavy lifting, twisting, bending, stooping, prolonged sitting, awkward posture at work, previous history of injury to the area) [6]. These are summarised in Table 1. Where high levels of evidence (Level I evidence) such as meta-analyses or systematic reviews were not available, less rigorous studies (Level II, III and IV evidence) were reported to represent the current levels of knowledge.

As part of a study investigating the prevalence of LBP in this community [3], the risk factors known to be associ- ated with LBP and other serious causes of morbidity and mortality were measured. This paper aims to describe the most commonly reported risk factors for LBP in a large rural Indigenous community; and examine their association with reported LBP as a basis for informing the development of a broad health promotion intervention in this community.

\section{Methods and materials Design}

A cross-sectional self-report survey (Kempsey survey) was conducted to determine the extent of risk factors (Table 1) and their association with LBP in the study community.

\section{Ethics: consent and approval}

Participating community members completed a consent form that explained the purpose of the survey. Ethics approval was obtained from the Durri Aboriginal Corporation Medical Service (ACMS) Board of Directors and the Human Research Ethics Committee of the University of Newcastle.

\section{Community consultation, collaboration and ownership of the program}

The Durri Community of Kempsey, NSW, Australia, comprises one of Australia's largest rural Aboriginal communities. The Durri (ACMS) is at the forefront of providing culturally appropriate care, largely via its Aboriginal Health Workers (AHWs). Durri ACMS aims to:

'make primary health care and education accessible to all members of the community in a culturally appropriate and spiritually sensitive manner, endeavouring to improve not only the health status but also the well-being of the Durri Aboriginal community' [13].

Discussions with a cross section of community members led to the formation of a Community Advisory Group (CAG) (which included representatives from the Durri ACMS, Booroongen Djugun Aboriginal Health Worker College, Hands On Health Australia and the University of Newcastle). The CAG aimed to advise on the development and implementation of the musculo-skeletal prevalence study [14]. Aboriginal Health Workers were chosen as the study agents because they are recognised as essential in providing culturally appropriate and effective health-care for their communities [15-22].

Community consultation occurred throughout the study. This process involved regular discussions with keyinformants from the community including AHWs, elders and health professionals. The community was informed of developments via information sheets and the publication of a summary report during the process and at the completion of the study. 
Table I: Individual modifiable risk factors associated with low back pain

\begin{tabular}{|c|c|c|}
\hline & $\begin{array}{l}\text { Factors strongly associated with LBP } \\
(\text { OR }>1.2-)\end{array}$ & $\begin{array}{c}\text { Factors moderately associated with } \\
\text { LBP (OR } \geq I-I .2-)\end{array}$ \\
\hline Lack of fitness/Physical inactivity & $\begin{array}{l}\text { Balague, } 1999[44]^{*} \\
\text { Feuerstein, } 1999[45] * * * *\end{array}$ & \\
\hline Smoking & $\begin{array}{l}\text { Balague, I } 999[44]^{*} \\
\text { Feldmann, } 1999[47]]^{* * *} \\
\text { Levangie, I } 999[48]^{* * *} \\
\text { Power, 2001[49] ** }\end{array}$ & Leboeuf-Yde, 1995[46]* \\
\hline Obesity & $\begin{array}{l}\text { Koda, } 1991[50] * * * * \\
\text { Alcouffe, } 1999[51] * * * * \\
\text { Walker, } 1999[52] * * \\
\text { Fransen, 2002[53] } * * * * \\
\text { Webb, 2003[55] } * * * * *\end{array}$ & 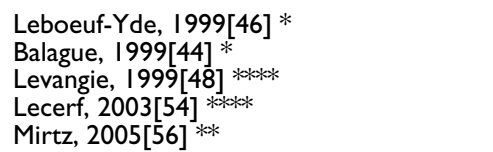 \\
\hline Psychosocial stress & 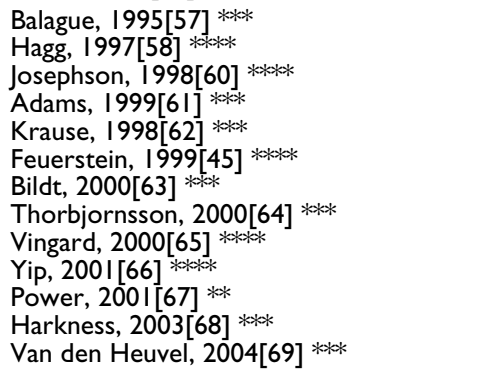 & $\begin{array}{l}\text { Balague, } 1999[44] * \\
\text { Hoogendorm, 2000[59] *** }\end{array}$ \\
\hline \multirow[t]{2}{*}{ Physical trauma } & $\begin{array}{l}\text { Harkness, 2003[68] }{ }^{* * *} \\
\text { Balague, I } 999[44]^{*}\end{array}$ & \\
\hline & $\begin{array}{l}\text { Factors strongly associated with LBP } \\
(\text { OR }>1.2-)\end{array}$ & $\begin{array}{c}\text { Factors moderately associated with } \\
\text { LBP (OR }>I-\mid .2-)\end{array}$ \\
\hline Awkward posture (at work) & $\begin{array}{l}\text { Koda, } 1991[50] * * * * \\
\text { Alcouffe, } 1999[51] * * * * \\
\text { Jin, } 2000[53] * *\end{array}$ & Picavet, $2000[70] * * *$ \\
\hline Frequent bending and twisting & $\begin{array}{l}\text { Alcouffe, } 1999[51] * * * * \\
\text { Hoogendoorm, } 2000[59] * * * \\
\text { Vingard, 2000[65] } * * * * \\
\text { Jin, 2000[7I] }{ }^{* *} \\
\text { Van den Heuvel, 2004[69] *** }\end{array}$ & Picavet, $2000[70]$ *** \\
\hline Heavy lifting, repetitive lifting & 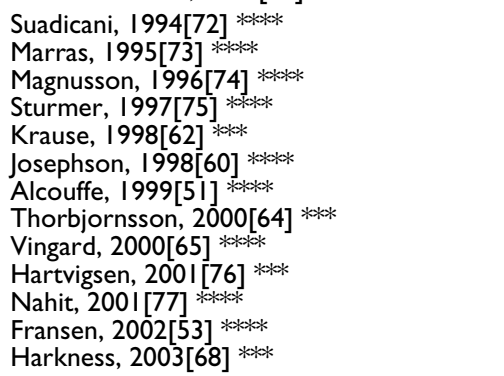 & \\
\hline Jarring, Gripping, vibration, repetitive actions & $\begin{array}{l}\text { Bongers, } 1993[78] * \\
\text { Magnusson, 1996[74] **** } \\
\text { Levangie, 1999[48] *** } \\
\text { Pope, 1999[79] *** } \\
\text { Jin, 2000[71] * }\end{array}$ & \\
\hline Prolonged sitting \& prolonged standing & $\begin{array}{l}\text { Burdorf, I994[80] } * * * * \\
\text { Bongers, I } 993[78] * * \\
\text { Thorbjornsson, 2000[64] } * * *\end{array}$ & Hartvigsen, $2000[81]$ *** \\
\hline
\end{tabular}

\section{NB: Only first authors included.}

Legend: + OR: Odds ratio

Level I evidence *, Level II evidence **, Level III evidence ***, Level IV evidence****

- Level I - based on studies such as meta-analyses or systematic reviews of all relevant randomised controlled trials (RCTs);

- Level II - based on well-designed RCTs;

- Level III - based on well-designed prospective or case-control analytical studies; and

- Level IV - based on opinions of respected authorities, clinical experience, descriptive studies and case reports or reports of expert committees. 
Table 2: Sensitivity, specificity and Kappa for LBP screening survey compared to clinical assessment $(n=189)$

\begin{tabular}{lcccccc}
\hline Survey results & \multicolumn{3}{c}{ Clinical Assessment } & & Specificity & $\begin{array}{c}\text { Kappa } \\
\text { coefficient }\end{array}$ \\
\cline { 2 - 5 } & Negative & Positive & Total & & 0.63 & 0.46 \\
Negative & 43 & 21 & 64 & 0.83 & \\
$\begin{array}{l}\text { Positive } \\
\text { Total }\end{array}$ & 25 & 100 & 125 & & \\
\hline
\end{tabular}

\section{Sample}

Our goal was to select a representative cross-sectional sample of the local Aboriginal community of sufficient size to generalise our major findings to the whole local community (population 550). A random sampling procedure stratifying for age and sex was used to derive a representative sample of the local community. The sample size was generated using Epi-Info 6 [23]. With a population size of 550, the expected frequency of the main variable of interest (low back pain) was estimated at 50\%. The value chosen as the farthest acceptable from the real population was $44 \%$. Using these values and a 95\% confidence interval, the ideal random sample size calculated was 180 . However, we expected that logistically this was unlikely to be achieved, as many of the sample selected were likely to be uncontactable given the transient nature of community residents [24]. Accordingly, where randomly selected community members were unable to participate, they were replaced using a convenience sampling approach to achieve the required sample size. Although this strategy was not ideal, all attempts were made to attain a representative sample. Participants within the community were selected from persons aged 15-years or older who had been previously identified as Aboriginal (according to the definition of Aboriginal adopted by the Department of Aboriginal Affairs Constitutional Section) [25]. These participants were recruited by distributing letters inviting them to contact the assisting AHWs at the ACMS. If no response was received within a week, an attempt to contact the person via telephone was made by the assisting AHW.

\section{Procedure}

The Kempsey survey included a screening survey administered by Aboriginal Health Workers immediately followed by a clinical conducted by chiropractors blinded to the findings of the screening survey.

Those who consented to participate were asked to attend the Durri ACMS. If participants found transport to the ACMS difficult, either the research team (including the researcher, the AHW and volunteer chiropractors/chiro- practic students) would travel to the participants' homes, or the assisting AHW would arrange for the Durri ACMS bus to provide transportation at no charge.

\section{Screening survey}

Participants completed a screening survey previously found to be culturally acceptable and sensitive in measuring musculo-skeletal conditions and associated risk factors in this community. The survey achieved satisfactory measurement agreement (Kappa scores) when compared to a clinical assessment performed by chiropractors (a proxy "Gold Standard") [22]. Although some authors argue that a 'Gold standard' does not exist in many areas of musculo-skeletal practice [26], standard clinical assessments performed by musculo-skeletal health professionals provide the best available tools for measuring painful and limited ranges of motion and a provisional diagnosis [27]. The purpose of the screening survey was to identify those who had experienced a musculo-skeletal condition including ache, pain or discomfort. The questionnaire also assessed self-reported limitations to Activities of Daily Living (ADL) imposed by pain.

Participants screened by the AHW-administered survey subsequently underwent a clinical examination conducted by four chiropractors previously trained and assessed in standard, clinical assessment procedures according to a procedural manual which outlined the cultural considerations and logistical processes required by researchers. The content of the procedural manual was revised in a two-hour workshop for participating researchers to clarify and standardise study requirements. The exam was based on accepted clinical parameters for conducting musculoskeletal conditions and included the domains of assessment used by teaching institutions [28]. Thus attempts were made to fulfil content and face validity.

\section{Assessment}

Participants attended a clinical assessment immediately following the screening survey to confirm the presence of musculo-skeletal conditions [22]. Chiropractors and 5th 
Table 3: Age and sex of study participants

\begin{tabular}{|c|c|c|c|c|c|c|}
\hline Age category (years) & Male & Female & Total & $\%$ Male & $\%$ Female & $\%$ Total \\
\hline $15-25$ & 20 & 20 & 40 & 23.0 & 19.6 & 21.2 \\
\hline $26-35$ & 14 & 16 & 30 & 16.1 & 15.7 & 15.9 \\
\hline $36-45$ & 25 & 29 & 54 & 28.7 & 28.4 & 28.6 \\
\hline $46-55$ & 13 & 10 & 23 & 14.9 & 9.8 & 12.2 \\
\hline $56+$ & 12 & 24 & 36 & 13.8 & 23.5 & 19.0 \\
\hline Unknown & 3 & 3 & 6 & 3.4 & 2.9 & 3.2 \\
\hline Total & 87 & 102 & 189 & 100 & 100 & 100 \\
\hline
\end{tabular}

year chiropractic students performed a follow-up clinical assessment (based on clinical assessment parameters used in 1999 at the School of Chiropractic, RMIT University, Victoria, Australia) [28] to validate the findings reported in the screening questionnaire.

A positive pain finding in the clinical assessment was derived by practitioner-based examination, including the patient's history of involved site(s) followed by standard orthopaedic and range of motion tests to localise sites of pain and restricted movement. A negative pain finding was indicated by the absence of reported pain and/or restricted orthopaedic and range of motion findings as examined by the practitioner. Trivial LBP was differentiated from important LBP using a Likert scale. High levels of pain were interpreted as those ranging between 6-10 on a Likert scale of $0-10$. Only those reporting "High" levels of pain were analysed in this study. Further questions related to any musculo-skeletal condition(s) experienced in the last seven days. In particular, probable causes of symptoms, past history, initial episode(s) of symptoms, duration of symptom(s), 'average' severity of symptoms and any associated limitation of daily activities. Also examined were, social routine and work activities, the type of treatment received and any barriers to receiving treatment were sought.

In the history component of the clinical assessment, chiropractors once again questioned participants about the presence of musculo-skeletal risk factors (according to the criteria reported in Table 1). Risk factor data were derived in the history component of the clinical assessment by asking questions from a list of modifiable occupational and lifestyle factors. Results for LBP as measured in the clinical assessment were used in the analysis. Clinical findings requiring follow-up treatment, management or referral was also identified.

Health workers using a laptop computer entered data onsite into a specifically designed, Microsoft Access database.

\section{Screening and assessment agreement}

The questionnaire results were compared to the data from the clinical examination and published in a previous study (Table 2). Eighty-three percent of all participants reporting LBP in the screening survey also tested positive for LBP via the clinical assessment. Sensitivity of the screening survey for LBP was 0.83 , specificity 0.63 and Kappa 0.46. Thus the screening survey achieved an adequate level of agreement with the clinical assessment [29].

\section{Measures}

The main variables of interest from the survey and clinical assessment were:

- Demographic and other sample characteristics-age, sex, number of children, occupation, weight, and Body Mass Index (BMI).

- Prevalence of LBP (within the last seven days, according to self report).

- Pain levels were recorded using a Likert scale where a score of 0 corresponded to no pain and 10 to severe pain.

- Duration of LBP was categorised as less than/equal to or more than seven weeks.

- Disability levels were recorded using a Likert scale where a score of 0 corresponded to no disability and 10 to severe disability. Disability was defined as "how much the condition (ache, pain or discomfort) had affected the participants ability to carry out daily activities (e.g., housework, washing, dressing, lifting, walking, driving, climbing stairs, getting in and out of bed or a chair, sleeping, working, social activities and sport)".

- Self-reported modifiable risk factors as described in Table 1 (according to a standardised clinical history).

- Other musculo-skeletal conditions. 
Table 4: Occupation of study participants according to sex

\begin{tabular}{|c|c|c|c|c|c|c|}
\hline Occupation & Male & Female & Total & $\%$ Male & $\%$ Female & \% Total \\
\hline Managers and Administrators & 5 & 3 & 8 & 5.7 & 2.9 & 4.2 \\
\hline Professionals & 7 & 9 & 16 & 8.0 & 8.8 & 8.5 \\
\hline Associate professionals* & 5 & 16 & 21 & 5.7 & 15.7 & 11.1 \\
\hline Tradespersons and related workers & 1 & 2 & 3 & 1.1 & 2.0 & 1.6 \\
\hline Advanced clerical and service workers & 3 & 2 & 5 & 3.4 & 2.0 & 2.6 \\
\hline Intermediate clerical, Sales and service workers & 3 & 2 & 5 & 3.4 & 2.0 & 2.6 \\
\hline Elementary Clerical, Sales and Service workers & 2 & 6 & 8 & 2.3 & 5.9 & 4.2 \\
\hline Labourers and Related workers & 13 & 3 & 16 & 14.9 & 2.9 & 8.5 \\
\hline Unemployed/Student & 38 & 28 & 66 & 43.7 & 27.5 & 34.9 \\
\hline Home duties & 1 & 16 & 17 & I.I & 15.7 & 9.0 \\
\hline Retired & 4 & 15 & 19 & 4.6 & 14.7 & 10.1 \\
\hline Unknown & & 5 & 0 & 5 & 0.0 & 2.6 \\
\hline Total & 87 & 102 & 189 & 100 & 100 & 100 \\
\hline
\end{tabular}

* Associate Professionals

\section{Analyses}

Frequencies and confidence intervals were reported for characteristics of the sample, prevalence of LBP and reported risk factors for low back pain. Chi-square analyses were performed to test for factors associated with low back pain. Given the number of variables, only significant associations were reported.

\section{Results}

Sample

The study was conducted between January 2001 and July 2002. The sample comprised 189 Indigenous people: 80 were selected randomly and the remainder were convenience sampled as described above.

\section{Sample characteristics}

Age and sex

The mean age of participants was 44 years $( \pm 14.8)$ and the median age 43 years. The sample comprised 87 males (46\%) and 102 females (53\%) ranging in age from 15 to 80 years. There were no significant differences in the distribution of males and females in the various age categories $(\mathrm{p}=0.35)$. Gender was comparable with previous ABS census data for Indigenous people in Australia [26]. Age categories were also similar in breakdown to those described in census data for the entire Indigenous community (Table 3) [30].

Despite a high consent rate (85\% of the randomly recruited sample), the response rate was low (40\%) because many members of this highly mobile community were unable to be contacted.
Number of children

Approximately one third (31\%) of participants had between two or three children. Thirty percent of participants had no dependent children and 17\% had 4-5 children. Of note, $15 \%$ had six or more children. These findings are comparable to those of other Indigenous studies [5]. An Australian Bureau of Statistics (ABS) study reported that Indigenous families tend to be larger than Australian families overall. According to the 1996 Census, approximately $13 \%$ of Indigenous families had four or more children compared with less than $5 \%$ of other Australian families [5].

\section{Occupation}

Occupational demographics of the participants in the study are summarised in Table 4. Approximately one third of the community surveyed were students or unemployed. A significant number of people surveyed were associate professionals, retired workers, involved in home duties or labourers. These data were generally comparable with those reported for Indigenous people by the ABS (2000). However, for males in the Kempsey survey, there were significantly less professionals, managers, tradespersons and transport workers, and more intermediate clerical, sales and service persons, compared to the ABS population. For females there were significantly more professional, and associates professionals (such as Aboriginal Health Workers), and less tradespersons or transport workers as well as many less intermediate clerical, sales and service persons, compared to the ABS population [5].

\section{$B M I$}

Table 5 shows that $32 \%$ of participants were overweight and 39\% were obese. Using Body Mass Index (BMI) esti- 
Table 5: Body Mass Index (BMI) of participants, according to age and sex $(n=189)$

\begin{tabular}{|c|c|c|c|c|c|c|c|c|c|c|c|}
\hline \multicolumn{12}{|c|}{ BMI classification } \\
\hline Age (yrs) & Sex & Normal & (\%) & Overweight & (\%) & Obese & (\%) & Unknown & (\%) & Total & (\%) \\
\hline \multirow[t]{3}{*}{$15-25$} & Male & 10 & $23 \%$ & 7 & $14 \%$ & 2 & $.02 \%$ & 0 & $0 \%$ & 19 & $10 \%$ \\
\hline & Female & 7 & $16 \%$ & 5 & $10 \%$ & 9 & $12 \%$ & 0 & $0 \%$ & 21 & $12 \%$ \\
\hline & Total & 17 & $39.5 \%$ & 12 & $24 \%$ & 11 & $14 \%$ & 0 & $0 \%$ & 40 & $22 \%$ \\
\hline \multirow[t]{3}{*}{$26-45$} & Male & 5 & $12 \%$ & 13 & $26 \%$ & 18 & $23 \%$ & 4 & $33 \%$ & 40 & $22 \%$ \\
\hline & Female & 14 & $33 \%$ & 9 & $18 \%$ & 18 & $23 \%$ & 5 & $42 \%$ & $46 \%$ & $25 \%$ \\
\hline & Total & 19 & $44 \%$ & 22 & $44 \%$ & 36 & $47 \%$ & 9 & $75 \%$ & 86 & $47 \%$ \\
\hline \multirow[t]{4}{*}{$>45$} & Male & 4 & $9 \%$ & 6 & $12 \%$ & 13 & $17 \%$ & 1 & $8 \%$ & 24 & $13 \%$ \\
\hline & Female & 3 & $7 \%$ & 10 & $20 \%$ & 17 & $22 \%$ & 2 & $17 \%$ & 32 & $18 \%$ \\
\hline & Total & 7 & $16 \%$ & 16 & $32 \%$ & 30 & $39 \%$ & 3 & $25 \%$ & 56 & $31 \%$ \\
\hline & TOTAL & 43 & $100 \%$ & 50 & $100 \%$ & 77 & $100 \%$ & 12 & $100 \%$ & 182 & $100 \%$ \\
\hline
\end{tabular}

Note: $\mathrm{BMI}=$ Weight $(\mathrm{kg})$ divided by square of height $(\mathrm{m})$

mates, 26\% (95\% CI: 20\%-32\%) of participants were overweight (BMI = 25.0-29.9) and 45\% (95\% CI: 38\%$52 \%)$ were obese $(\mathrm{BMI}=30.00)$. The high prevalence of obesity in this study agrees with national figures demonstrating a greater prevalence of obesity among Indigenous people than non-Indigenous Australians [5].

Self-Report of LBP within the last seven days

The prevalence of all LBP (i.e. including all levels of pain) within the last seven days was 72\% (95\% CI: 63\%-80\%) and all LBP lasting seven weeks or longer was 34\% (95\% CI: $27 \%-40 \%)$.

\section{Previous history of LBP}

Previous history of LBP was present in 34\% (95\% CI: $27 \%-40 \%$ ) of respondents. A previous history of LBP is known to predispose individuals to recurrent episodes of back pain [31].

\section{Other modifiable risk factors for LBP \\ Smoking}

Smoking was highly prevalent 46\% (95\% CI: 38\%-53\%) in the community, with equal numbers of males and females smoking. Thirty eight per cent (95\% CI: 31\%$45 \%$ ) of people smoked between 10-20 cigarettes daily and 8\% (95\% CI: .04\%-11\%) smoked more than 20 cigarettes per day. This is consistent with the 2001 National Health Survey (NHS), which found that $51 \%$ of Indigenous people aged 18 years or older were current smokers, compared with $24 \%$ of non-Indigenous people [32].

\section{Physical inactivity}

Sixteen percent (95\%CI: 10\%-21\%) of participants spent no time actively exercising and 35.9\% (95\% CI: $26 \%-$ $45 \%$ ) exercised less than 30 minutes per week. There are no other detailed data available on the levels of physical activity among Indigenous people. However, the 2001 NHS reported that $43 \%$ of Indigenous people aged 18 years or older living in non-remote areas were sedentary, compared with $30 \%$ of non-Indigenous people [32].

\section{Psychosocial stress}

For those reporting LBP 72\% (CI: 65\%-78\%), the most commonly reported traumatic events included sporting injuries 26.5\% (95\% CI: 20\%-38\%), motor vehicle accidents 18\% (95\% CI: 12\%-23\%) and work-related trauma $17.5 \%$ (95\% CI: 12\%-22\%). There was, however, no association between LBP and physical trauma.

\section{Physical trauma}

For those reporting LBP (66.1\% CI: 54\%-68\%), the most commonly reported traumatic events included sporting injuries 26.5\% (95\% CI: 20\%-38\%), motor vehicle accidents 18\% (95\% CI: $12 \%-23 \%)$ and work-related trauma $17.5 \%$ (95\% CI: 12\%-22\%). There was, however, no association between LBP and physical trauma.

\section{Occupational risk factors}

Figure 1, Modifiable occupational risk factors for musculo-skeletal conditions details reported occupational risk factors for LBP. Common risk factors were adopting awk- 


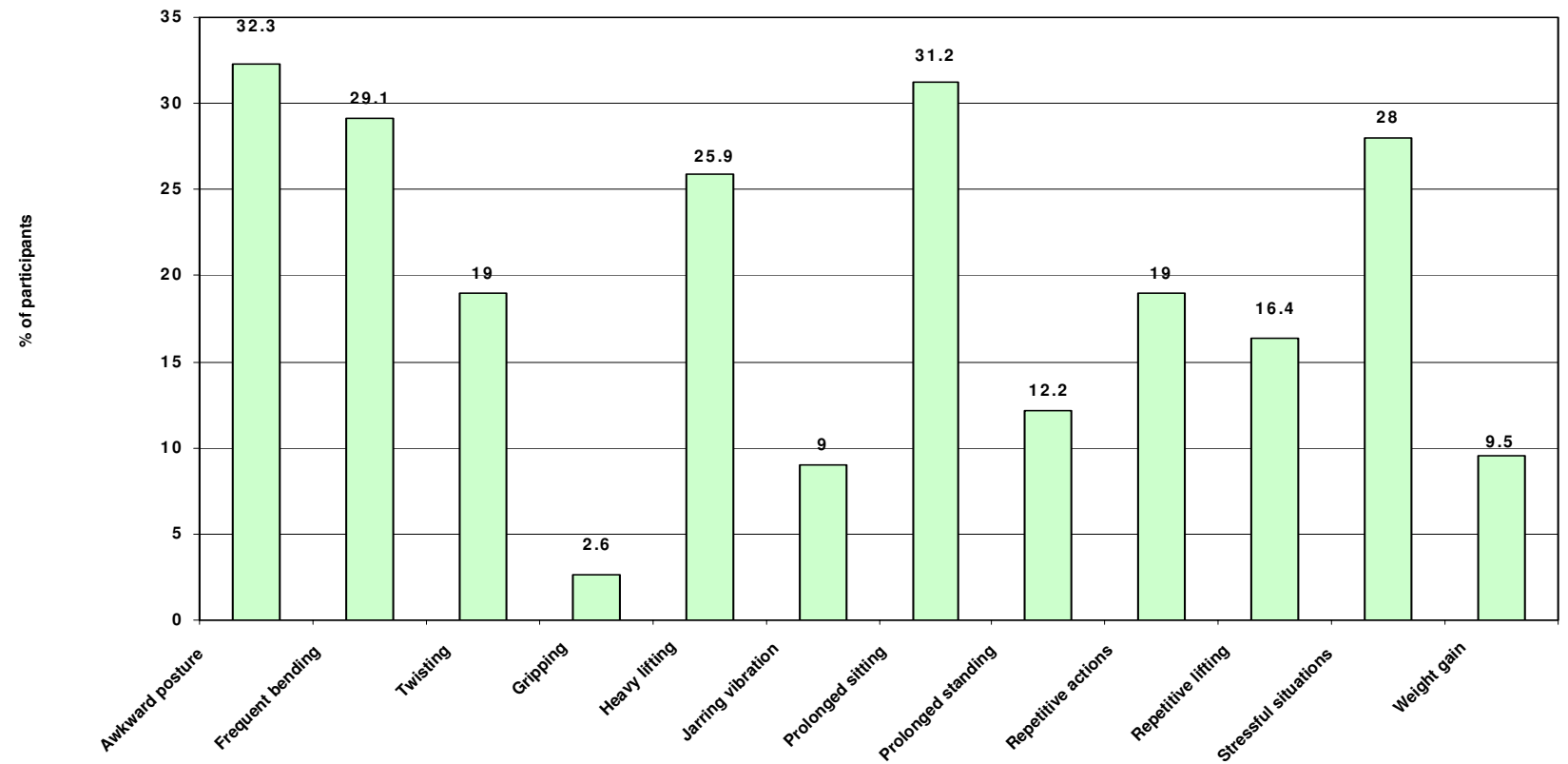

Figure I

ward postures at work 32\% (95\% CI: 25\%-39\%), frequent bending and twisting 29\% (95\%: CI: 22\%-35\%) and heavy lifting 26\% (95\% CI: 20\% - 32\%). However, there was no association between LBP and occupational risk factors.

\section{Factors associated with reported LBP}

Even though a trend was evident, no statistical association between LBP and the lifestyle factors detailed above. However, more participants reporting high levels of LBP were overweight or obese and obesity was statistically associated with self-reported strain causing reported LBP $\left(\chi^{2}=9.02, \mathrm{df}=210, \mathrm{p}=0.01\right)$. While sporting injuries were not statistically associated with report of LBP in particular, participants reporting sporting injuries experienced between two and four musculo-skeletal conditions $\left(\chi^{2}=7.90, \mathrm{df}=2, \mathrm{p}=0.02\right)$.

\section{Discussion}

The $72 \%$ seven day prevalence of LBP found in the Kempsey survey is greater than similar prevalence levels reported in other rural Indigenous Communities $[1,2,33,34]$. In their study, Honeyman and Jacobs [2] reported a 1-day LBP prevalence for the majority of community members, 68\% (95\% CI: 61\%-74\%). The majority of participants in the Kempsey survey also experienced their presenting LBP for seven weeks or more. Thus according to accepted definitions of chronicity [35], the majority of Indigenous people in this Community were suffering from chronic pain and were therefore, likely to be at greater risk of enduring prolonged disability [31]. Thirty-four percent of participants also reported a previous history of LBP, which was likely to predispose them to recurrent, future episodes [31]. Furthermore, trauma particularly that incurred in sporting injuries was associated with multiple musculo-skeletal conditions. Past studies have reported that Indigenous people are more likely to experience transport accidents, intentional self-harm and assault than other Australians with rates approximating three times those of the rest of the Australian population [32].

The findings in this study of higher levels of smoking, physical inactivity and obesity are consistent with those reported by other studies of Indigenous Australians [9]. Though many of the modifiable risk factors known to be associated with LBP were highly prevalent in this study, none of these were statistically associated with LBP. One explanation for this finding is that the size of the sample, though sufficiently large to demonstrate comparability with ABS findings for demographic categories, may not have been sufficiently large to achieve the statistical power 
to detect any association between LBP and associated study factors.

Obesity and physical inactivity are the two most important modifiable factors contributing to the development of type 2 diabetes mellitus. These factors were highly prevalent in the community with $26 \%$ of subjects overweight, $45 \%$ obese and $16 \%$ spending no time actively exercising plus a further $35.9 \%$ exercising less than 30 minutes per day. Exercising was assessed by self-report according to total time spent exercising ranging from 'No time' to 'More than 10 hours per week'. Obesity in this study was associated with self-reported low back strain. The prevalence of obesity in this community is of concern, first because obesity is an independent predictor of back pain [36], but more importantly as obesity has a global health impact.

Health providers including chiropractors and osteopaths commonly counsel LBP sufferers to lose weight to unload their spines. Weight loss also offers other musculo-skeletal benefits. Females with a BMI of over $25 \mathrm{~kg} / \mathrm{m} 2$, can, by losing $5 \mathrm{~kg}$ ( 2 BMI units) reduce future onset of knee osteoarthritis by $50 \%$ and males by $25 \%$ [37]. Obesity has also been associated with a higher prevalence of work limitations, hypertension, dyslipidemia, type 2 diabetes and the metabolic syndrome in adults of working age [38]. Furthermore, Australia-wide some 50\% of cases of type 2 diabetes are asymptomatic, undiagnosed and persons subclinically undergo progressive macro and micro-vascular changes [39]. The current findings suggest that screening this population group for evidence of glucose intolerance when reviewing musculo-skeletal conditions such as LBP may be valuable.

Of those reporting LBP, $72 \%$ of participants (CI: 65\%$78 \%$ ) were frequently exposed to "stressful situations" in their occupation. However, psychosocial stress outside of the work place was not measured given the cultural sensitivity of this factor according to the CAG. Psychosocial stress in general is a strong predictor of LBP $[40,41]$. If conducted in a culturally appropriate manner, future studies assessing LBP in Indigenous Communities should ideally attempt to also measure psychosocial stress as a potential contributing study factor.

Another concurrent health hazard is the high prevalence of cigarette smoking. In addition to the well documented risks of smoking it has been found that compared with matched groups of non-smokers, chronic cigarette smokers are more likely to be insulin resistant, hyperinsulinemic, and dyslipidemic [39].

Exercise is the most common method of treating LBP in Australia [42]. In addition it may be the single most important lifestyle factor for both preventing and reversing insulin resistance, particularly among obese individuals $[12,13]$. This suggests a good case for concentrating on general exercise health promotion for Indigenous communities.

Lifestyle interventions incorporated into a culturally sensitive health promotion program could potentially benefit the health and modify the morbidity and mortality of this population group. These results suggest an opportunity to review and address risk factors associated with LBP along with more serious diseases affecting Indigenous people. Addressing modifiable risk factors associated with LBP, such as smoking, physical inactivity, and obesity could significantly contribute to the management of co-morbidities including diabetes and heart disease which so commonly affect Indigenous Australians.

An understanding of the modifiable risk factors for LBP identified in this paper also formed the basis for a culturally acceptable musculo-skeletal intervention designed to address the high prevalence of LBP. This involved using a pilot training program for Aboriginal Health Workers (AHWs). The intervention was designed to promote the musculo-skeletal and general health of Indigenous people living in this rural community [12]. Culturally sensitive approaches to managing musculoskeletal conditions have been successfully implemented in other Indigenous Communities [43].

The Community Oriented Program for the Control of the Rheumatic Diseases (COPCORD) represents the largest, ongoing collaborative attempt to measure the prevalence of musculo-skeletal conditions and risk factors in rural populations throughout the world [43]. COPCORD has also developed implemented and evaluated culturally sensitive approaches for managing these conditions and their associated risk factors through community-based initiatives with applicability in other Indigenous Communities.

We propose that any future musculo-skeletal study or intervention in an Indigenous community be accompanied by a review of the modifiable risk factors associated with LBP and counselling about those factors. This may have a beneficial effect on the overall well being of indigenous communities. Further research should test such a program for efficacy and effectiveness.

\section{Conclusion}

The disturbingly high prevalence of LBP experienced in this community necessitates a serious response. Managing LBP through health services and addressing the modifiable risk factors through culturally sensitive, health promotion programs will be an important step in addressing the 
high burden of illness imposed by LBP and other more serious conditions suffered in this community.

\section{Competing interests}

Dr. Bruce Walker is Editor-in-Chief of Chiropractic \& Osteopathy.

\section{Acknowledgements}

The authors would like to acknowledge the assistance of the Durri ACMS, NSW, as well as the Booroongen Djugun College, NSW, The Murray School of Health Education, NSW, and volunteers from the RMIT University, Victoria, Australia. The authors also thank Hands on Health Australia for funding the program. Also, Dr janice Perkins for introducing the authors to the community and assisting in the design of the original program from which this study was drawn, Mrs Karen Woulfe for kindly proof-reading the text, Michael Dalton for data and statistical consultancy and Julie Bateman for formatting the paper.

\section{References}

I. Mayhew C: Aboriginal and Torres Strait Islander occupational health and safety: a pilot study in Queensland. Australian Aboriginal Studies 1996, 2:61-8.

2. Honeyman PT, Jacobs EA: Effects of culture on back pain in Australian aboriginals. Spine 1996, 21(7):84I-3.

3. Vindigni D, Griffen D, Parkinson J, Da Costa C, Parkinson L: The prevalence of musculo-skeletal conditions, associated pain and disability and the barriers to managing these conditions in a rural, Australian Aboriginal Community. Rural and Remote Health $2004 \quad$ http://rrh.deakin.edu.au/contributenew/contrib view.asp?ArticlelD=230].

4. Boreham P, Whitehouse G, Harley B: The labour force status of Aboriginal people: a regional comparison. Labour and Industry 1993, 5(I):16-32.

5. Australian Institute of Health and Welfare: Australia's Health 2000: the seventh biennial health report of the Australian Institute of Health and Welfare. Canberra: AlHW; 2000.

6. Haldeman S: Risk factors for low back and neck pain: An introduction to clinical epidemiology and review of commonly suspected risk factors. In Principles and Practice of Chiropractic 3rd edition. Edited by: Hartvigsen J. The McGraw-Hill Companies; 2005:465-483

7. Dwyer AP: Backache and its prevention. Clin Orthop 1987 222:35-43.

8. Farrelly P: Ergonomic Applications in the Workplace for Clients with Low Back Pain. In Proceedings of Commonwealth Rehabiitation Conference Melbourne; 1991.

9. Mathers $C$, Penm RV: Health system costs of injury, poisoning and musculoskeletal disorders in Australia 1993-94. In AlHW Australian Institute of Health and Welfare, AlHW Cat. No. HWE I2: Health and Welfare Expenditure Series No 6 Canberra: AlHW; 1999.

10. Pill RM, Jones-Elwyn G, Stott NC: Opportunistic health promotion: quantity or quality? JR Coll Gen Prac 1989, 39(322): 196-200.

II. Lehmann R, Vokac A, Niedermann K, et al.: Loss of abdominal fat and improvement of the cardiovascular risk profile by regular moderate exercise training in patients with NIDDM. Diabetologia 1995, 38:1313-1319.

12. Kelley DE, Goodpaster B, Wing RR, Simoneau JA: Skeletal muscle fatty acid metabolism in association with insulin resistance, obesity and weight loss. Am J Physiol 1999, 277:EI I30-EI|4.

13. Durri Aboriginal Corporation Medical Service: Annual Report. 2000-200I. Kempsey, NSW, Durri Aboriginal Corporation Medical Service 200I.

14. Vindigni D, Parkinson L, Blunden S, Perkins J, Rivett D, Walker B: Aboriginal health in Aboriginal hands: Development, delivery and evaluation of a training program for Aboriginal Health Workers to promote the musculoskeletal health of indigenous people living in a rural community. Rural and Remote Health 2004:28I [http://rrh.deakin.edu.au/articles/showarti clenew.asp?ArticlelD=28I].
15. Saggers S, Gray D: In Aboriginal Health and Society: the traditional and contemporary Aboriginal struggle for Better Health. Sydney, Allen and Unwin; 1991.

16. Ezzy J: Competency based nutrition education and training for trainee Aboriginal health workers at Batchelor College. In Nutrition Networks ' 95 Conference. Proceedings of the 4th National Conference 'Waranyjarrigun Yagarrama Yagarrayirr' Gathering and Sharing'; Broome, Western Australia; 1995.

17. Doyle M], et al:: Training Koori Health Workers for Effective Community-based Eye care Services. Ninth National Health Promotion Conference People, Places and Programs. Darwin . 18-20 May, 1997

18. Keefe J, McCarthy C, Doyle M, Taylor H: The Rumbalara Eye Care Project: initial results of vision screening by Aboriginal health workers. In Proceedings, 28th Annual Conference of the Public Health Association of Australia, Threats to Public Health Challenges and Strategies Perth, Western Australia. 29 September-2 October 1996

19. Doyle M, Keefe J, McCarthy C, Harper C, Taylor H: Training Koori Health Workers for effective community-based eye care services. In AAHP and PHA [HPSIG] Ninth National health promotion Conference. People Places and Programs: exploring better practice and health promotion for diverse populations Darwin. 18-20 May, 1997

20. Pacza T, Steele L, Tennant M: Dental train-the-trainer program for Aboriginal health workers in the Kimberley Region. In Report prepared by the School of Oral Health Sciences The University of Western Australia, Nedlands 6907; 2000.

21. Clifford A, Atkinson D: Aboriginal and Torres Strait Islander Health Worker Training in Western Australia. In Conference Proceeding Perth; 2000:31-39.

22. Vindigni $D$, Perkins J, Blunden S: The prevalence of musculoskeletal conditions among Indigenous people living in rural Australia: an opportunity for health promotion? Aboriginal \& Torres Strait Islander Health Worker Journal 2003, 27(2):4-8.

23. Epi-Info Version 6.04. Center for Disease Control and Prevention (CDC), Atlanta; 1997.

24. Donovan RJ, Spark R: Towards guidelines for survey research in remote Aboriginal Communities. Aust NZJ Public Health 1997, $21(1): 89-95$.

25. Department of Aboriginal Affairs Constitutional Section: Report on a Review of the Administration of the Working Definition of Aboriginal and Torres Strait Islander Canberra; Department of Aboriginal Affairs; 2000.

26. Beruskens AJ, de Vet HC, Koke AJ, van der Heijden G], Knipschild PG: Measuring the functional status of patients with low back pain. Assessment of the quality of disease-specific questionnaires. Spine 1995, 20(9): 1017-1028

27. Guidelines for Chiropractic Quality Assurance and Practice Parameters (Mercy Guidelines). Edited by: Haldeman S, Chapman-Smith D, Petersen DM. Consensus Conference Commissioned by the Congress of Chiropractic State Associations. Mercy Conference Center, Burlingame, California, USA; 1992.

28. Protocol, School of Chiropractic, RMIT. History and clinical assessment proforma for 4th and 5th year student preceptorship; Bundoora, Victoria; RMIT School of Chiropractic; 1999.

29. Jekel J, Elmore J, Katz D: Epidemiology, Biostatistics and Preventive Medicine Philadelphia: W.B. Saunders Company; 1996

30. Australian Bureau of Statistics: Experimental estimates of the Aboriginal and Torres Strait Islander population, 30 June 1991 - 30 June 1996. Canberra; Australian Bureau of Statistics; 1998.

31. Frymoyer JW: Back pain and sciatica. N Engl J Med 1988, 318(5):291-300.

32. Australian Bureau of Statistics: National Aboriginal and Torres Strait Islander survey detailed findings: 1995. Canberra, Australian Bureau of Statistics; 1994.

33. Lee TG: Indigenous Health. A Needs Assessment Study of the Outer Eastern Metropolitan Region of Melbourne. Detailed Report, Yarra Ranges Health Service, Victoria, a member of the inner and Eastern Health Care Network; 1998.

34. McLennan W, Madden R: The Health and Welfare of Australia's Aboriginal and Torres Strait Islander Peoples. In ABS Catalogue no. 4704.00 AlHW Catalogue no. IHW 3 Canberra, Australian Bureau of Statistics \& the Australian Institute of Health and Welfare; 1999.

35. National Advisory Committee on Health and Disability: New Zealand Acute Low Back Pain Guide. Wellington, New Zealand, 
Ministry of Health, Manatu Hauora. National Health Committee; 1999.

36. Webb R, Brammah T, Lunt M, Urwin M, Allison T, Symmons D: Opportunities for prevention of 'clinically significant' knee pain: results from a population-based cross sectional survey. J Public Health (Oxf) 2004, 26(3):277-84.

37. Meisler JG, St Jeor S: ADA Position: Weight Management. Journal of the American Dietetic Association 1997, 97(I): I996.

38. Hertz RP, Unger AN, McDonald M, Lustik MB, Biddulph-Krentar The Impact of Obesity on Work Limitations and Cardiovascular Risk Factors in the U.S. Workforce. J Occup Environ Med 2004, 46(1 2): I 196-1 203.

39. Facchini FS, Hollenbeck CB, Jeppersen J, et al.: Insulin resistance and cigarette smoking. Lancet 1992, 339: I I 28- II30.

40. Papageorgiou AC, Macfarlane G], Thomas E, et al.: Psychosocial fac tors in the workplace-do they predict new episodes of low back pain? Evidence from the South Manchester Back Pain Study. Spine 1997, 22(1 0): I I 37-42.

4I. Adams MA, Mannion AF, Dolan P: Personal risk factors for firsttime low back pain. Spine 1999, 24(23):2497-505.

42. Walker BF, Muller R, Grant WD: Low back pain in Australian adults. health provider utilization and care seeking. J Manipulative Physiol Ther 2004, 27(5):327-35

43. Muirden KD: The Origins Evolution and Future of COPCORD. APLAR. Journal of Rheumatology 1997, I:44-8.

44. Balague F, Troussier B, Salminen J]: Non-specific low back pain in children and adolescents: risk factors. Eur Spine 1999, J8(6):429-38.

45. Feuerstein M, Berkowitz SM, Huang GD: Predictors of occupational low back disability: implications for secondary prevention. J Occup Environ Med 1999, 4I(I 2): I024-3I.

46. Leboeuf-Yde C, Yashin A: Smoking and low back pain: is the association real? J Manipulative Physiol Ther 1995, I 8(7):457-63.

47. Feldman DE, Rossignol M, Shrier I, Abenhaim L: Smoking. A risk factor for development of low back pain in adolescents. Spine 1999, 24(23):2492-6.

48. Levangie PK: Association of Low Back Pain with Self-Reported Risk Factors Among Patients Seeking Physical Therapy Services. Physical Therapy 1999, 79(8):. Research Report

49. Power C, Frank J, Hertzman C, Schierhout G, Li L: Predictors of low back pain onset in a prospective British study. Am J Public Health 200I, 9 I(I 0): I67|-8.

50. Koda S, Hisashige A, Ogawa T, Kurumatani N, Dejima M, Miyakita T, Kodera R, Hamada H, Nakagiri S, Aoyama H: An epidemiological study on low back pain and occupational risk factors among clinical nurses. Sangyo Igaku 1991, 33(5):410-22. [Article in Japanese]

51. Alcouffe J, Manillier P, Brehier M, Fabin C, Faupin F: Analysis by sex of low back pain among workers from small companies in the Paris area: severity and occupational consequences. Occup Environ Med 1999, 56( I 0):696-70I

52. Walker BF: The prevalence of low back pain in Australian adults. A systematic review of the literature from I9661998. Asia-Pacific Journal of Public Health 1999, I I ( I):45-5I.

53. Fransen $M$, Woodward $M$, Norton R, Coggan C, Dawe M, Sheridan $\mathrm{N}$ : Risk factors associated with the transition from acute to chronic occupational back pain. Spine 2002, 27(I):92-8.

54. Lecerf JM, Reitz C, Chasteigner AD: Evaluation of discomfort and complications in a population of I 8102 overweight or obese patients. Presse Medicale 2003, 32(I 5):689-95.

55. Webb R, Brammah T, Lunt M, et al.: Prevalence and Predictors of Intense, Chronic, and Disabling Neck and Back Pain in the UK General Population. Spine 2003, 28(I I): I I95-202.

56. Mirtz TA, Greene L: Is obesity a risk factor for low back pain? An example using the evidence to answer a clinical question. Chiropr Osteopat 2005, I3:. Published online 2005 April II. doi: 10.1186/1746-1340-13-2

57. Balague F, Skovron ML, Nordin M, et al.: Low back pain in schoolchildren. A study of familial and psychological factors. Spine 1995, 20( I I): | 265-70.

58. Hagg GM, Astrom A: Load pattern and pressure pain threshold in the upper trapezius muscle and psychosocial factors in medical secretaries with and without shoulder/neck disorders. Int Arch Occup Environ Health 1997, 69(6):423-32.

59. Hoogendoorm WE, Bongers PM, de Vet HC, et al.: Flexion and rotation of the trunk and lifting at work are risk factors for low back pain: results of a prospective cohort study. Spine 2000, 25(23):3087-92.

60. Josephson M, Vingard E: Workplace factors and care seeking for low-back pain among female nursing personnel. MUSICNorrtalje Study Group. Scand J Work Environ Health 1998, 24(6):465-72.

6I. Adams MA, Mannion AF, Dolan P: Personal risk factors for firsttime low back pain. Spine 1999, 24(23):2497-505.

62. Krause N, Ragland DR, Fisher JM, Syme SL: Psychosocial job factors, physical workload, and incidence of work-related spinal injury: a 5-year prospective study of urban transit operators. Spine 1998, 23(23):2507-16.

63. Bildt C, Alfredsson L, Michelsen H, et al:: Occupational and nonoccupational risk indicators for incident and chronic low back pain in a sample of the Swedish general population during a 4-year period: an influence of depression? International Journal Behavioral Medicine 2000, 7(4):372-92.

64. Thorbjornsson CB, Alfredsson L, Fredriksson K, Michelsen H, Punnett L, Vingard E, Torgen M, Kilbom A: Physical and psychosocial factors related to low back pain during a 24-year period. A nested case-control analysis. Spine 25(3):369-74. 2000 Feb I, discussion 375

65. Vingard $E$, Alfredsson L, Hagberg $M$, et al:: To what extent do cur rent and past physical and psychosocial occupational factors explain care-seeking for low back pain in a working population? Results from the Musculoskeletal Intervention CenterNorrtalje Study. Spine 2000, 25(4):493-500.

66. Yip Y: A study of work stress, patient handling activities and the risk of low back pain among nurses in Hong Kong. J Adv Nurs 200I, 36(6):794-804.

67. Power C, Frank J, Hertzman C, Schierhout G, Li L: Predictors of low back pain onset in a prospective British study. Am J Public Health 200I, 9 I(I0): I67I-8.

68. Harkness EF, Macfarlane GJ, Nahit ES, Silman AJ, McBeth J: Risk factors for new-onset low back pain among cohorts of newly employed workers. Rheumatology (Oxford) 2003, 42(8):959-68

69. van den Heuvel SG, Ariens GA, Boshuizen HC, Hoogendoorn WE, Bongers PM: Prognostic factors related to recurrent low-back pain and sickness absence. Scand J Work Environ Health 2004, 30(6):459-67.

70. Picavet HS, Schouten JS: Physical load in daily life and low back problems in the general population. The MORGEN study. Prev Med 2000, 3 I (5):506-I2.

7I. Jin K, Sorock GS, Courtney T, et al.: Risk factors for work-related low back pain in the People's Republic of China. Int J Occup Environ Health 2000, 6(I):26-33.

72. Suadicani $P$, Hansen K, Fenger AM, Gyntelberg F.: Low back pain in steel plant workers. Occup Med (Lond) I994, 44(4):2। 7-2I.

73. Marras WS, Lavender SA, Leurgans SE, Fathallah FA, Ferguson SA, Allread WG, Rajulu SL: Ergonomics: Biomechanical risk factors for occupationally related low back disorders. 1995 , 38(2):377-410

74. Magnusson ML, Pope MH, Wilder DG, Areskoug B: Are occupational drivers at an increased risk for developing musculoskeletal disorders? Spine 1996, 2 I(6):710-7.

75. Sturmer T, Luessenhoop S, Neth A, Soyka M, Karmaus W, Toussaint R, Liebs TR, Rehder U: Construction Work and Low Back Disorder: Preliminary Findings of the Hamburg Construction Worker Study. Spine 22(2I):2558-2563. 1997 November I

76. Hartvigsen J, Bakketeig LS, Leboeuf-Yde C, Engberg M, Lauritzen T: The association between physical workload and low back pain clouded by the "healthy worker" effect: populationbased cross-sectional and 5-year prospective questionnaire study. Spine 26(16): 1788-92. 200। Aug 15, discussion 1792-3

77. Nahit ES, Macfarlane GJ, Pritchard CM, Cherry NM, Silman AJ: Short term influence of mechanical factors on regional musculoskeletal pain: a study of new workers from I 2 occupational groups. Occup Environ Med 200 I, 58(6):374-8I.

78. Bongers PM, de Winter CR, Kompier MA, Hildebrandt VH: Psychosocial factors at work and musculoskeletal disease. Scand Work Environ Health 1993, I9(5):297-3I2.

79. Pope $M H$, Wilder DG, Magnusson ML: A review of studies on seated whole body vibration and low back pain. Proc Inst Mech Eng $[H]$ 1999, $213(6): 435-46$. 
80. Burdorf A, Naaktgeboren B, de Groot HC.: Occupational risk factors for low back pain among sedentary workers. J Occup Med 1993, 35(12): 1213-20.

8I. Hartvigsen J, Leboeuf-Yde C, Lings S, Corder EH: Is sitting-whileat-work associated with low back pain? A systematic, critical literature review. Scand J Public Health 2000, 28(3):230-9.

Publish with Bio Med Central and every scientist can read your work free of charge

"BioMed Central will be the most significant development for disseminating the results of biomedical research in our lifetime. " Sir Paul Nurse, Cancer Research UK

Your research papers will be:

- available free of charge to the entire biomedical community

- peer reviewed and published immediately upon acceptance

- cited in PubMed and archived on PubMed Central

- yours - you keep the copyright

Submit your manuscript here:

http://www.biomedcentral.com/info/publishing_adv.asp
BioMedcentral 